\title{
Renal Dysplasia in a Maltese Dog
}

\author{
Thais Nascimento de Andrade Oliveira Cruz ${ }^{1}$, Juneo Freitas Silva², Fabiana Lessa Silva ${ }^{3}$, \\ \& Renata Santiago Alberto Carlos ${ }^{3}$
}

\begin{abstract}
Background: Renal dysplasia (RD) is a common cause of renal failure in young dogs. It is defined as a disorganization in renal parenchymal development, with abnormal differentiation. In all domestic animal species, RD may be hereditary or acquired. The affected animals show clinical signs of early chronic kidney disease, usually between 3 months to 3 years of age. The alterations include persistent metanephric ducts surrounded by primitive mesenchyme, glomeruli and fetal tubules, and abnormal interstitial fibrous tissue. We aimed to report the case of a 1-year-old canine with renal dysplasia. Case: A 1-year-old male Maltese dog experiencing polyuria, polydipsia, recurrent episodic vomiting, bloody diarrhea, weight loss, apathy, and anorexia was referred to a private clinic in the municipality of Itabuna-Bahia. Physical examination revealed hypochromic mucosa, dehydration estimated at $8 \%$, rectal temperature of $37.5^{\circ} \mathrm{C}$, halitosis, and a body score of 3 out of 9 . Laboratory abnormalities included hematocrit of $18 \%$, with hypochromic normocytic aregenerative anemia, azotemia (urea $-530 \mathrm{mg} / \mathrm{dL}$, creatinine $-10.5 \mathrm{mg} / \mathrm{dL}$ ), hyperglobulinemia (4.7 g/dL), low urinary density (1005), proteinuria $(300 \mathrm{mg} / \mathrm{dL})$, and urinary $\mathrm{pH}-7.0$. Ultrasonography revealed bilateral small kidneys with loss of corticomedullary definition, cystic formations of different sizes on the renal surface, and hyperechoic areas in the parenchyma; these alterations were suggestive of bilateral chronic nephropathy. Considering the clinical, hematological, biochemical, and ultrasonographic presentation associated with the age of the patient, renal dysplasia was suspected. The patient's clinical condition progressed to loss of consciousness and convulsions, followed by death. Necropsy revealed pale, hypotrophic kidneys with firm consistency, irregular capsular surface containing multiple cortical cysts of different sizes, and altered cortico-medullar proportion.. Kidney fragments were sent to the Laboratory of Histopathology of the State University of Santa Cruz. Histopathological analysis revealed a marked alteration of renal architecture with glomeruli and immature tubules (adenomatous aspect), persistent primitive mesenchyme, and remnants of the metanephric ducts, as well as tubular dilatation associated with marked interstitial fibrosis, discrete lymphohistiocytic interstitial nephritis, and multifocal areas of mineralization.

Discussion: The clinical changes observed in the present case occurred as a consequence of chronic kidney failure caused by RD and included anorexia, apathy, vomiting, bloody diarrhea, polyuria, polydipsia, and dehydration. These alterations were also found in other reported cases. The macroscopic findings were similar to those described in the literature and are characteristic of chronic kidney disease: small, firm, pale-colored kidneys. Microscopic changes of renal dysplasia include persistent metanephric ducts surrounded by primitive mesenchyme, glomeruli and fetal tubules, and abnormal interstitial fibrous tissue. In the histopathological renal evaluation in the present report, morphological alterations compatible with the described alterations in the literature were observed, thus allowing the diagnosis of renal dysplasia. Renal dysplasia can affect young dogs of different breeds, causing clinical manifestations of chronic kidney disease. In view of this, this disease should be included as a differential diagnosis in patients under 3 years old who present signs of chronic nephropathy.
\end{abstract}

Keywords: dog, juvenile kidney disease, renal insufficiency. 


\section{INTRODUCTION}

Chronic renal failure (CRF) is a clinical syndrome and an important cause of morbidity and mortality in dogs and cats $[2,13]$. Regardless of the etiology, during the evolution of a chronic renal disease, glomerular, tubular, and interstitial involvement of the glomerulus occurs, resulting in morphofunctional changes and consequent reduction in the glomerular filtration rate (GFR) [13]. It is characterized by a decreased ability to concentrate urine, clinically manifested by polyuria, and by the difficulty to maintain water and electrolyte homeostasis [2]. When CRF occurs in young dogs, it is usually associated with juvenile or familial nephropathies [4,7], which include disorders such as agenesis, renal dysplasia and hypoplasia, primary cystic disease, tubulo-interstitial diseases, glomerulopathies, and tubular dysfunction [7].

Renal dysplasia (RD) is a common cause of renal failure in young dogs. It is defined as disorganization in renal parenchymal development with abnormal differentiation $[7,10]$. In all species, RD may have a hereditary or acquired cause [5]. Dogs of the Shih Tzu, Lhasa Apso, Golden Retriever, Alaskan Malamute, and Chow Chow breeds are genetically more susceptible to this disease [10]. Affected animals present with clinical manifestations of early chronic kidney disease, usually between 3 months to 3 years of age $[5,11]$. Dysplastic kidneys present characteristics of chronic nephropathy with morphological alterations divided into three groups: primary dysplastic lesions, compensatory alterations, and degenerative and inflammatory lesions [13]. This article reports the case of a 1-year-old Maltese dog with renal dysplasia who developed CRF.

\section{CASE}

A 1-year-old male Maltese dog was referred to a private clinic in the municipality of Itabuna-BA, with complaints of polyuria and polydipsia for 3 days, episodes of recurrent vomiting, bloody diarrhea, weight loss, apathy, and anorexia. Physical examination showed hypochromic mucosa, marked dehydration, temperature of $37.5^{\circ} \mathrm{C}$, halitosis, and a body score 3 out of 9 [9].

Considering the clinical examination and the anamnesis, a suspicion of nephropathy was established, and investigations including Complete Blood Count (CBC), serum biochemistry, urinalysis, and ultrasonographic examination of the total abdomen were conducted.
CBC revealed hematocrit of $18 \%$, hemoglobin of $7.2 \mathrm{~g} / \mathrm{dL}$, erythrocyte level below normal values (2.56 million $/ \mathrm{mm}^{3}$ ), as well as reticulocyte values of $5,000 / \mu \mathrm{L}$, evidencing hypochromic, normocytic, and aregenerative anemia. Biochemical tests demonstrated elevation of urea $(530 \mathrm{mg} / \mathrm{dL})$ and creatinine $(10,2$ $\mathrm{mg} / \mathrm{dL})$ levels, hyperproteinemia $(7,9 \mathrm{mg} / \mathrm{dL})$ due to hyperglobulinemia $(4,7 \mathrm{~g} / \mathrm{dL})$, and a slight increase of alanine aminotransferase (100 U/L).

Urine summary revealed low urinary density (1005), proteinuria (300 mg/dL) and pH 7.0. The sediment presented squamous and renal cells, $>5$ red blood cells per field and $>3$ leukocytes per field.

The ultrasonographic examination showed that the kidneys were bilaterally reduced in size (more pronounced in the left kidney), as well as loss of the cortico-medullary definition, with cystic formations of different sizes on the renal surface and hyperechoic areas in the renal parenchyma. These changes were consistent with bilateral chronic nephropathy.

Considering the clinical, hematological, biochemical, and ultrasonographic presentation associated with the age of the patient, renal dysplasia was suspected.

As part of the treatment, a blood transfusion was requested, which was not authorized by the owner. In order to treat the anemia, a vitamin supplement based on folic acid and iron (Metacell Pet $\left.{ }^{\circledR}\right)^{1}$ in the dose of $1 \mathrm{~mL} / 10 \mathrm{~kg}$ orally every $24 \mathrm{~h}$. Supportive treatment with ranitidine hydrochloride in the dose of $1 \mathrm{~mL} / \mathrm{kg}$, subcutaneously, every $8 \mathrm{~h}$, metoclopramide $\left(\text { Plasil }^{\circledR}\right)^{2}$ in the dose of $0.5 \mathrm{mg} / \mathrm{kg}$, every $8 \mathrm{~h}$ by intramuscular route and omeprazole $\left(\text { Gaviz }^{\circledR}\right)^{3}$ in the dose of $1 \mathrm{mg} /$ $\mathrm{kg}$, orally every $24 \mathrm{~h}$, was prescribed for vomiting. The patient underwent parenteral fluid therapy $(\mathrm{NaCl} 0.9 \%)$ at an estimated dose of $40 \mathrm{~mL} / \mathrm{kg} /$ day for three days. In addition, supportive treatment was prescribed with hypercaloric vitamin supplement (Nutralife intensiv $\left.{ }^{\circledR}\right)^{4}$ 2 measures every $24 \mathrm{~h}$, Renadog $^{\circledR 5} 2$ small measures every $24 \mathrm{~h}$. After 3 days, investigations for urea (325 $\mathrm{mg} / \mathrm{dL})$ and creatinine $(5.25 \mathrm{mg} / \mathrm{dL})$ were repeated, which showed a significant improvement, with clinical worsening of the patient's condition. One week after begining of treatment, the patient returned to the clinic with convulsive episodes, which were treated with diazepam $(1 \mathrm{mg} / \mathrm{kg} \mathrm{IV})^{3}$, but without success, culminating with death. After authorization of the owner, necropsy was performed. 
At necropsy, the kidneys were very pale, hypotrophic, with a firm consistency, and an irregular capsular surface containing multiple cystic spaces of different sizes in the renal cortex (Figure 1). A reduced cortico-medullary relation was observed on the cut surface (Figure 1). In addition to renal changes, areas of ulceration were observed in the stomach and small intestine. Kidney fragments were sent to the Laboratory of Histopathology of the State University of Santa Cruz. Microscopic analysis revealed a marked alteration of the renal architecture with glomeruli and immature tubules (adenomatous aspect), persistent primitive mesenchyme and remnants of metanephric ducts, as well as tubular dilation associated with marked interstitial fibrosis, discrete lymphohistiocytic interstitial nephritis, and multifocal areas of mineralization (Figure 3).

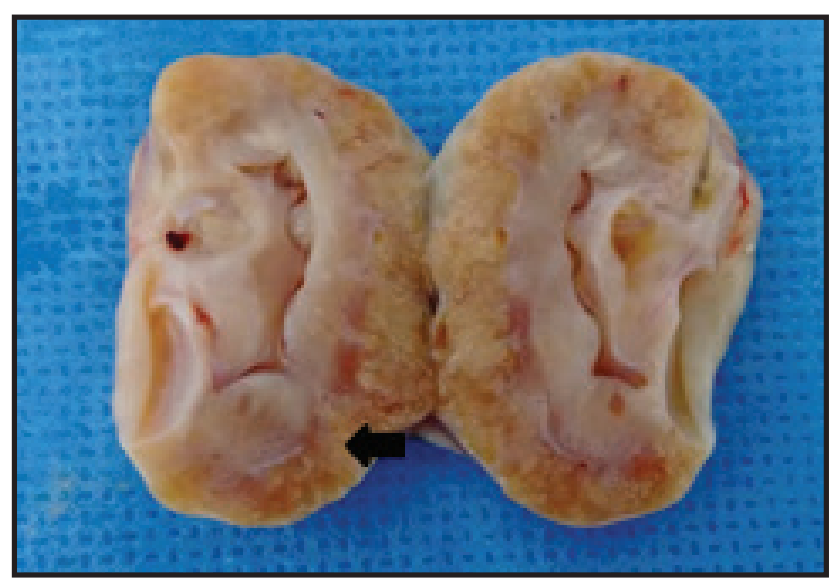

Figure 1. Macroscopic view of the cut surface of the dysplastic kidney of a 1-year-old Maltese dog. Note the reduced kidney size, white color, and altered cortico-medullary relationship (black arrow).

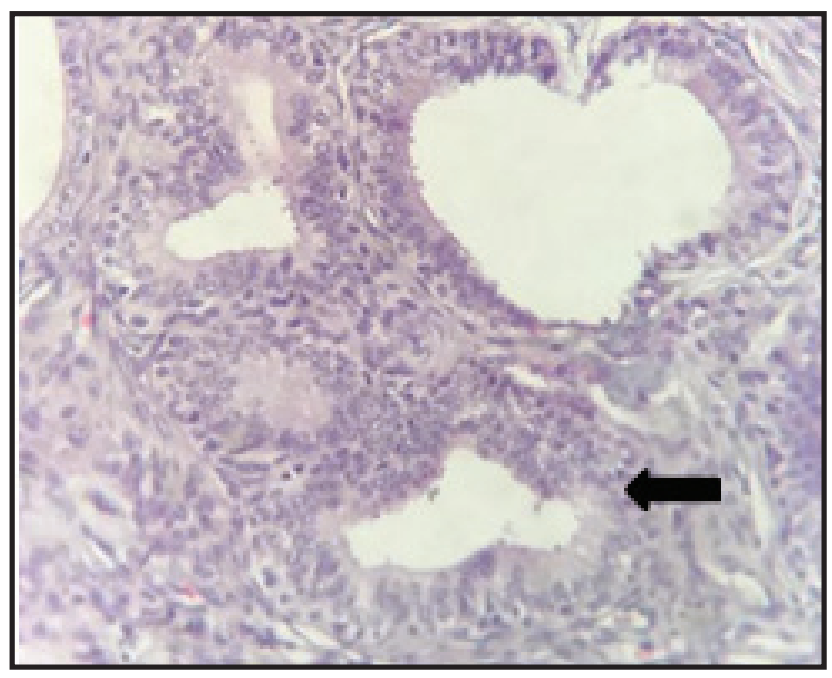

Figure 2. Histological section of the dysplastic kidney (100x). Note the remaining mesonephric ducts (black arrow).

\section{DISCUSSION}

The clinical changes observed in the subject of the present report occurred as a consequence of chronic kidney failure caused by RD and included anorexia, apathy, vomiting, bloody diarrhea, polyuria, polydipsia, and dehydration. These alterations have also been reported in cases reported by other authors $[6,13,14]$. Polyuria and polydipsia result from the inability of the kidneys to concentrate urine even though the animal is dehydrated, due to loss of hypertonicity of the medullary interstitium and high filtrate flow in the remaining nephrons [7]. Anorexia and vomiting are the result of stimulation of the chemoreceptor zone by uremic toxins, gastritis that develops due to direct injury by uremic toxins, and by increased gastrin concentrations, causing excessive production of gastric acid and production of ammonia from urea [2].

The aregenerative anemia presented by the patient was mainly due to the reduction in erythropoietin production. This is perhaps the most significant hematologic finding described in the literature [8]. Increased urea and creatinine serum concentrations confirmed renal failure, a terminal condition of patients with RD that has also been described by other authors [8]. In cases of aregenerative anemia secondary to CRF, the most effective therapy is with human erythropoietin; however, the medication is not easily

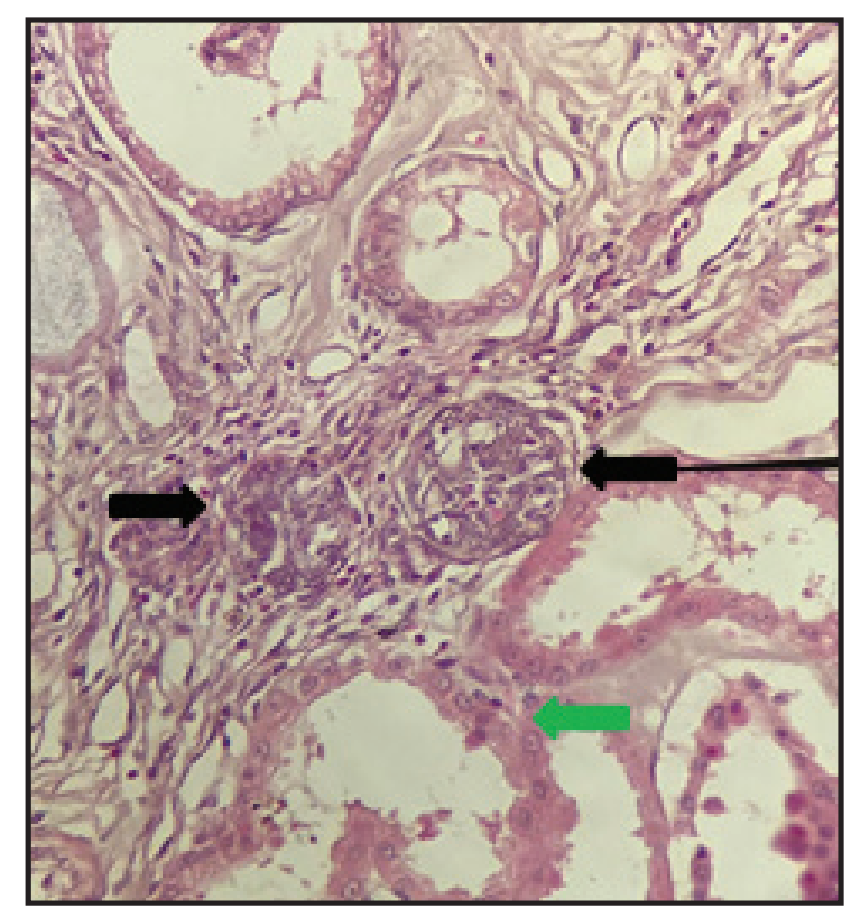

Figure 3. Histological cut of the dysplastic kidney (400x). The fetal glomeruli (black arrow) and dilated renal tubules (green arrow) are visible. 
accessible in the region. The treatment instituted to control anemia was included the use of multivitamins based on folic acid, and ferrous sulfate. Some animals may present improvement of anemia with only vitamin supplementation [12].

The animal was administered fluid therapy aimed at the correction of dehydration and consequent improvement of renal perfusion. Polyuria, vomiting, and diarrhea contribute to dehydration, reduction of renal perfusion, and worsening of renal function. Therefore, fluid therapy with crystalloids (Ringer's lactate or $0.9 \% \mathrm{NaCl}$ ) is indicated [7]. Gastrointestinal disorders contribute to anorexia and weight loss [7]. The treatment performed in this case to control gastrointestinal complications is in accordance with the literature, which recommends the administration of drugs such as ranitidine hydrochloride and omeprazole [12]. Omeprazole specifically inhibits the $\mathrm{H}^{+} / \mathrm{K}^{+}$-ATPase enzyme in the parietal cells of the stomach, whereas ranitidine has histamine antagonistic action, reducing acid secretion in the stomach [12]. Metoclopramide has an antiemetic action, in addition to increasing the tone and strength of gastric contractions and relaxing the pyloric, duodenal, and jejunal sphincters, resulting in accelerating gastric emptying and intestinal transit [12].

Ultrasound abnormalities of renal dysplasia may exhibit a variety of characteristics depending on the degree of organ involvement by inflammatory processes and fibrosis, which occurs as a consequence of dysplasia [1]. However, the alterations found in this case corroborate with those cited in the literature, which include irregular edges, loss of corticomedullary proportion and delimitation, and presence of cysts that are identified ultrasonographically as areas of defined and regular limits, presenting anechoic content within them.

The macroscopic findings were similar to those described in the literature [12] and are characteristic of chronic renal disease, mainly due to the secondary fibrosis process, resulting in small, firm, and pale-colored kidneys. Reports of dysplastic kidneys with presence of cysts have also been reported by other authors $[12,14]$. These cysts may be multiple and of varying sizes, from 0.1 to $5 \mathrm{~cm}$ in diameter, and may be distributed on the subcapsular and cut surface [12]. At cut surface, attention is drawn to cortical-medullary alteration and dilation of the pelvis, similar to descriptions in the literature [12]. The differential diagnosis for this type of macroscopic presentation would be the terminal kidney that occurs in older dogs [3].

Microscopic alterations in dysplastic kidneys are classified as: primary lesions characterized by the presence of immature or fetal glomeruli, mesangial tissue and persistent metanephric duct, atypical tubular epithelium, or dysontogenetic metaplasia; compensatory alterations evidenced by metaplasia or glomerular and tubular hypertrophy; and inflammatory or degenerative lesions represented by nephritis/pyelonephritis, interstitial fibrosis, dystrophic mineralization, cystic glomerular atrophy, and glomerular lipidosis $[6,14]$. In the histopathological evaluation of the kidney of this report, morphological alterations observed were compatible with the three types of alterations described in the literature, allowing for a conclusive diagnosis of renal dysplasia.

Renal dysplasia can affect young dogs of different breeds, causing clinical manifestations of chronic kidney disease. In view of this, this disease should be included as a differential diagnosis in patients under the age of 3 years who present with signs of chronic nephropathy.

\section{MANUFACTURERS}

${ }^{1}$ Ouro Fino Saúde Animal Ltda. Osasco, SP, Brazil.

${ }^{2}$ Sanofi, São Paulo, SP, Brazil.

${ }^{3}$ Agener União Saúde Animal Ltda. São Paulo, SP, Brazil.

${ }^{4}$ Vetnil Ltda, Louveira, SP, Brazil.

${ }^{5}$ Bioctal Comércio de Produtos Veterinários Ltda, Valinhos, SP, Brazil.

Declaration of interest. The authors report no conflicts of interest. The authors alone are responsible for the content and writing of the paper.

\section{REFERENCES}

1 Babicsak V.R., Zardo K.M., SSantos D.R., Bellota A.F., Oliveira H.S., Mamprim M.J., Machado V.M.V. \& Vulcano L.C. 2012. Contribuição da ultrassonografia para o diagnóstico da displasia renal em cães. Veterinária e Zootecnia. 19(2): 181-185.

2 Guimarães L.L.B., Reis M.O., Hesse K.L., Boabaid F.M., Pavarini S.P., Sonne L. \& Driemeier D. 2014. Achados patológicos em caninos com displasia renal no Sul do Brasil. Pesquisa Veterinária Brasileira. 34(12): 1227-1230. 
3 Hunning P.S., Aguiar J., Lacerda L.A., Sonne L., Oliveira E.C. \& Haas G.F. 2009. Displasia renal em um cão. Acta Scientiae Veterinariae. 37(1): 73-77.

4 Laflamme D.P. 2006. Understanding and managing obesity in dogs and cats. Veterinary Clinics Small Animal Practice. 36(6): 1283-1295.

5 Lees G.E. 1996. Congenital Renal Diseases. Veterinary Clinics of North America: Small Animal Practice. 26(6): 1379-1399.

6 Lima S.R., Silva L.A., Dias G.B.G., Lopes L.L., Cruz, R.A.S., Sonne L., Pescador C.A. \& Colodel E.M. 2017. Displasia renal em cães: estudo retrospectivo (2008-2013). Acta Scientiae Veterinariae. 45(Suppl. 1): 184

7 Lustoza M.D. \& Kogika M.M. 2003. Tratamento da Insuficiência renal crônica em cães e gatos. Revista Brasileira de Medicina Veterinária- Pequenos Animais e Animais de Estimação. 1(1): 62-69.

8 Notomi M.K., Kohika M.M., Ikesaki, J.YY.H., Monteiro P.R.G. \& Marquesi M.L. 2006. Estudo retrospectivo de casos de insuficiência renal crônica em cães no período de 1999 a 2002. Brazilian Journal of Veterinary Research and Animal Science. 43(Suppl.): 12-22.

9 Ohara K., Kobayashi Y., Tsuchiya N., Furuoka H. \& Matsui T. 2001. Renal dysplasia in a Shih Tzu dog in Japan. Journal of Veterinary Medical Science. 63(10): 1127-1130.

10 Polzin D.J., Osborne C.A., Jacob F. \& Ross S. 2008. Insuficiência renal crônica, In: Ettinger S.J. \& Feldman E.C. (Eds). Tratado de Medicina Interna Veterinária: Doenças do Cão e do Gato. 5.ed. Rio de Janeiro: Guanabara Koogan, pp.1721-1751.

11 Picut C.A. \& Lewis R.M. 1987. Microscopic features of canine renal dysplasia. Veterinary Pathology. 24(2): 156-163.

12 Rubin S.I. 1997. Chronic renal failure and its management and nephrolithiasis. Veterinary Clinics of North America: Small Animal Practice. 27(6): 1331-1354.

13 Volkweis F.S., Almeida A.M.S., Wong L., Mulinari F. \& Santos Júnior H.L. 2012. Displasia renal em cão da raça Rotweiller. Arquivo Brasileiro de Medicina Veterinária e Zootecnia. 64(6): 1511-1514.

14 Whiteley M.H. 2014. Allelic variation in the canine Cox-2 promoter causes hypermethylation of the canine Cox-2 promoter in clinical cases of renal dysplasia. Clinical Epigenetics. 6(1): 7. 